\title{
A Prospective Study Comparing Continuous Versus Interrupted Suture Techniques in Midline Abdominal Wound Closure
}

\author{
Bharti SV ${ }^{1}$, Sharma $A^{1}$
}

\section{ABSTRACT}

Introduction: Wound closure after midline laparotomy is an essential part of surgery to produce a healthy and a strong scar. There is an alternative interrupted method of closure as compared to conventional continuous method of closure. Many comparative studies have shown different outcomes. So, we wanted to evaluate the outcome of different techniques in our setting. Aim: To compare the outcome of Interrupted abdominal closure and continuous abdominal closure in midline laparotomy wound. Methods: This was a prospective comparative study conducted in the Department of Surgery of Nepalgunj Medical College Teaching Hospital, Kohalpur, Banke, Nepal for a duration of 1 year. A total of 60 patients were selected randomly to receive either continuous or interrupted abdominal closure in midline laparotomy wound. Wound was evaluated in terms of wound discharge, infection and wound dehiscence. Results: The mean age of the patients was 38.38 years. Most commonly, the patients presented with duodenal ulcer perforation with peritonitis. The average time taken for abdomen closure in group A (16.77 minutes) was significantly less as compared to group B (27.77 minutes). The average cost of sutures for group B (Rs 1322.97) was higher than that of sutures for group A (Rs 1118) with $p$ value of $<0.01$. Wound infection and incidence of burst abdomen were similar in both groups after one month, suture sinus was seen in three patients of group $A$ and four patients of group $B$ ( $p=1.0$ ). Incisional hernia was seen in one patient of group A and in none of the patients of group B at three month's follow-up ( $p=1.0)$. Conclusion: Continuous technique of midline laparotomy wound closure is better in terms of time required for wound closure and costing of suture materials, while showing no difference in terms of wound infection, burst abdomen and late wound complications.

Keywords: Abdominal closure, Continuous technique, Interrupted technique, Midline laparotomy

Authors:

1. Dr. Shiv Vansh Bharti

2. Dr. Anup Sharma

${ }^{1}$ Department of Surgery, Nepalgunj Medical College and Teaching Hospital, Kohalpur, Banke

\section{Address for Correspondence:}

\author{
Dr. Shiv Vansh Bharti \\ Department of Surgery \\ Nepalgunj Medical College and Teaching Hospital \\ Kohalpur, Banke, Nepal \\ Email: shivbharti2984@gmail.com
}

\section{INTRODUCTION}

Midline laparotomy incision provides adequate exposure to all four quadrants, allows rapid exposure with minimal blood loss and is simple, so it is the most prevalent technique to open the abdomen in both emergency and elective settings. ${ }^{1}$ However, it's drawbacks are comparatively increased incidence of postoperative wound dehiscence and incisional hernia as compared to other incisions. ${ }^{2,3,4}$

The elite technique of wound closure would be the one that approximates the tissue in such a way that normal healing mechanisms can occur under optimal circumstances. The technique should provide adequate tensile strength to the incision until the wound is healed and remains secure even in the presence of local or systemic infection, and should be the one in which suture material is well tolerated on a short and long-term basis. The technique should be able to be done with expediency. ${ }^{3}$ Different methods for closure of laparotomy wounds have been used in the past. The abdomen closure has been done in terms of continuous versus interrupted closure, single layer versus mass closure and absorbable versus non absorbable sutures. ${ }^{4}$ The selection of material for closing the abdominal fascia should be made with the knowledge of what is known about fascial healing and the physical properties of suture material (strength, durability, ease of handling, and resistance to infection). ${ }^{5}$ The advantage of continuous suturing technique is that it provides equally distributed tension across the suture line and is more expedient, but its disadvantage is that it has a single suture holding the fascia together. The interrupted suturing technique has been used with success in the past, but its drawback is that it is tedious and there is a need of isolating tension to each individual stitch. ${ }^{3}$

Studies carried out in the past have shown non uniform results regarding the risk of burst abdomen between continuous 
and interrupted methods. ${ }^{6,7,8}$ The selection of technique for abdominal closure may not be very important in elective laparotomies with adequate nutritional status and with no other risk factors for burst abdomen, but in a developing country like Nepal, many patients in emergency conditions present with malnutrition and prolonged intraperitoneal sepsis which are the risk factors for burst abdomen. Hence, it is important for us to determine the optimal technique for abdominal closure in our group of such patients. ${ }^{7}$

\section{METHODS}

This prospective comparative study was conducted in Department of Surgery, Nepalgunj Medical College Teaching Hospital, Kohalpur, Banke, Nepal for a duration of 1 year from July 2018 to June 2019. A total of 60 cases (30 cases in each group) undergoing emergency laparotomy were included.

Ethicon's prolene (polypropylene) number 1 round body was used in all patients. The method of abdomen closure for each case was determined by the next sequence number from a randomization chart and the patients were divided into two groups. Group A consisted of patients whose wound was closed by continuous closure technique and Group B, whose wound was closed using interrupted abdominal closure technique.

The abdomen was closed in a single layer using Polypropylene number 1 in both groups. In Group A suture was placed at least $1.5 \mathrm{~cm}$ away from the fascial edge and a distance of $1 \mathrm{~cm}$ was kept in between each suture. A strand of suture was started at the end of the incision placing the knots underneath the fascia, and then the sutures were run towards each other and tied in the middle of the incision. ${ }^{3}$ In Group B, suture was placed at least $1.5 \mathrm{~cm}$ away from the fascial edge and a distance of 1 $\mathrm{cm}$ was kept in between each suture. Here, Smead-Jones farfar, near-near technique was used. ${ }^{3}$ In both the techniques, sutures were tied such that the fascial edges well approximated but not crushed together. ${ }^{3}$ The length of the wound, number of suture packs used and time consumed (in minutes) for closure were recorded intra-operatively. Wound was evaluated for erythema, swelling, serous discharge, infection, separation of edges and wound dehiscence postoperatively. If wound discharge was present, it was sent for culture and sensitivity. Early wound complications like serous discharge, partial wound dehiscence (dehiscence of skin and subcutaneous tissue with intact musculoaponeurotic layer), wound infection and burst abdomen were observed until the patients were discharged. Patients were called in for follow-up after one month and after three months of discharge to look for late wound complications like suture sinus formation and incisional hernia. The data so collected was analyzed using IBM SPSS (Statistical Package for the Social Studies) version 21. Student's T test, Chi-square test and Fisher's exact test were applied for statistical significance with $\mathrm{p}$ value of $<0.05$.

\section{RESULTS}

The age of the patients ranged from two years to 72 years with mean age of 38.38 years (SD \pm 18.97 ). In group $A$ the youngest patient was aged two years and the oldest was 72 years, with a mean age of 36.23 years (SD \pm 20.88 ). Group B had a three years old patient as the youngest and 68 years old patient as the oldest with mean age of 40.53 years (SD \pm 16.92 ). The most common age group was $40-50$ years with 11 patients (18.3\%) and the least common was $>70$ years with two patients $(0.03 \%)$.

Both groups were comparable in terms of age distribution ( $p$ $=0.385)$.

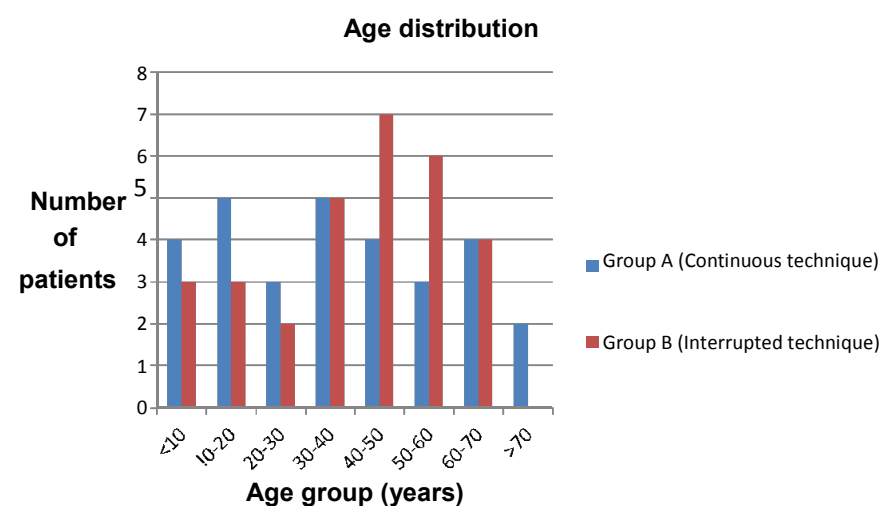

Figure 1: Age distribution (years)

Most commonly, patients presented with hollow viscus perforation with peritonitis. Out of 60 patients, 26 patients (43.33\%) had duodenal ulcer perforation, six patients $(10 \%)$ had appendicular perforation, six patients $(10 \%)$ had traumatic small bowel perforation, four patients(6.66\%) had sigmoid volvulus, four $(6.66 \%)$ had small bowel volvulus and four $(6.66 \%)$ patients had adhesive bowel obstruction.

The time taken for abdomen closure using continuous technique (16.77 $\mathrm{min}$ ) showed statistically significant difference over interrupted technique (27.77 $\mathrm{min}$ ) with $\mathrm{p}$ value of $<0.01$.

\begin{tabular}{|lccc|}
\hline \multicolumn{1}{|c}{ Group } & N & $\begin{array}{c}\text { Mean time taken for } \\
\text { abdomen closure }\end{array}$ & $\begin{array}{c}\text { Std. } \\
\text { Deviation }\end{array}$ \\
\hline Group A (Continuous technique) & 30 & $16.77 \mathrm{~min}$ & \pm 2.096 \\
\hline Group B (Interrupted technique) & 30 & $27.77 \mathrm{~min}$ & \pm 3.773 \\
\hline
\end{tabular}

Table I : Time taken for wound closure (minutes)

The average cost of sutures for group B (interrupted technique) was NRs 1322.97. Its cost was significantly higher than that of sutures for group A (continuous technique) whose average cost was NRs 1118 with $p$ value of $<0.01$.

There were no early wound complications in 15 (50\%) patients of group B and 17 (56.6\%) patients of group A.

In group A, five (16.7\%) patients had serous discharge while six (20\%) patients in group B had serous discharge $(p=0.739)$. 
In group A, five (16.7\%) patients had partial wound dehiscence (superficial skin and subcutaneous tissue dehiscence with intact musculoaponeurotic layer) while seven (23.3\%) patients had partial wound dehiscence in group $B(p=0.519)$.

In group $\mathrm{A}$, three $(10 \%)$ patients had burst abdomen while two (6.7\%) patients in group $B$ had burst abdomen $(p=1.0)$.

\begin{tabular}{|c|c|c|c|}
\hline \multirow[b]{2}{*}{ Wound Complication } & \multicolumn{2}{|c|}{ Abdomen Closed With } & \multirow[b]{2}{*}{ Total } \\
\hline & $\begin{array}{c}\text { Continuous } \\
\text { Technique Group A }\end{array}$ & $\begin{array}{c}\text { Interrupted } \\
\text { Technique Group B }\end{array}$ & \\
\hline Serous Discharge & 5 & 6 & 11 \\
\hline $\begin{array}{l}\text { Partial Wound } \\
\text { Dehiscence }\end{array}$ & 5 & 7 & 12 \\
\hline Burst Abdomen & 3 & 2 & 5 \\
\hline No Complication & 17 & 15 & 32 \\
\hline Total & 30 & 30 & 60 \\
\hline
\end{tabular}

Five (16.7\%) patients of group A had wound infection and six (20\%) patients of group B had infected wound with $p$ value of 0.739 . At one month follow up, suture sinus was seen in three (10\%) patients of group A and four (13.3\%) patients of group $B(p=1.0)$. At three month's follow up, suture sinus was seen in one (3.3\%) patient of Group A and two (6.7\%) patients of group $B(p=1.0)$. Incisional hernia was seen in only one $(3.3 \%)$ patient in group $A(p=1.0)$.

\begin{tabular}{|c|c|c|c|}
\hline \multirow[b]{2}{*}{$\begin{array}{l}\text { Wound at One } \\
\text { Month }\end{array}$} & \multicolumn{2}{|c|}{ Abdomen Closed With } & \multirow[b]{2}{*}{ Total } \\
\hline & $\begin{array}{c}\text { Continuous } \\
\text { Technique Group A }\end{array}$ & $\begin{array}{c}\text { Interrupted } \\
\text { Technique Group B }\end{array}$ & \\
\hline Suture Sinus & 3 & 4 & 7 \\
\hline $\begin{array}{l}\text { No Wound } \\
\text { Complication }\end{array}$ & 27 & 26 & 53 \\
\hline Total & 30 & 30 & 60 \\
\hline \multicolumn{4}{|c|}{ Table III : Wound complications at one month } \\
\hline \multirow[b]{2}{*}{$\begin{array}{c}\text { Wound at Three } \\
\text { Months }\end{array}$} & \multicolumn{2}{|c|}{ Abdomen Closed With } & \multirow[b]{2}{*}{ Total } \\
\hline & $\begin{array}{c}\text { Continuous } \\
\text { Technique Group A }\end{array}$ & $\begin{array}{c}\text { Interrupted } \\
\text { Technique Group B }\end{array}$ & \\
\hline Suture Sinus & 1 & 2 & 3 \\
\hline Incisional Hernia & 1 & 0 & 1 \\
\hline $\begin{array}{l}\text { No Wound } \\
\text { Complication }\end{array}$ & 28 & 28 & 56 \\
\hline Total & 30 & 30 & 60 \\
\hline
\end{tabular}

Table IV : Wound complications at three months

\section{DISCUSSION}

Wound closure after midline laparotomy is an essential part of surgery to produce a healthy and a strong scar. In the present study, the time taken for abdominal wound closure was significantly less with the use of continuous technique (16.77 $\mathrm{min}$ ) as compared to interrupted technique (27.77 $\mathrm{min}$ ). Study by Richards et al. showed similar result in which they randomized 571 patients and found out that the abdominal wounds could be closed by continuous suture in approximately half the time required for placing interrupted sutures (20 vs. 40 minutes). ${ }^{3}$

The cost of suture Ethicon's Prolene (polypropylene) no.1 round body used in this study is Rs 559 per suture. In this study, the cost of continuous abdominal closure (group A) was cheap compared to interrupted abdominal closure (group B). Almost single extra suture was required in interrupted abdominal closure for longer incisions. Since the abdomen was closed with continuous technique using two prolene sutures, which were started at both ends of the incision and then tied in the middle, the cost of the continuous suturing was the cost of two sutures. On the other hand, interrupted closure technique required two to three sutures for abdominal closure. Other studies by Fagniez et $\mathrm{al}^{9}$ Gislason et $\mathrm{al}^{10}$ and Dhamnaskar et al. ${ }^{11}$ concluded that continuous closure was preferable to interrupted closure in midline abdominal closure because it was more economic and expedient. Early wound complications were present in nearly half of patient population. However, the incidence of wound infection was statistically insignificant between the groups. While Karwasara et al. in their study, found out that interrupted closure group had more wound infection compared to continuous technique ( $28 \%$ vs. $16 \%){ }^{4}$

Hodgson et $\left.a\right|^{12}$ Shashikala et $\left.a\right|^{13}$ and Peponis et $\left.a\right|^{14}$ showed that wound infections were not statistically different between the two methods of abdomen closure. Incidence of wound infection rate was considerably high in our study than in other studies. It may be because our study was done exclusively in emergency cases and were of type IV wounds.

Worldwide incidence of wound dehiscence after midline laparotomy ranges from $0.9 \%$ to $36.7 \%$. $^{3,4,6,14,15}$ Burst abdomen was present in $8.33 \%$ of the patients in this study. Burst abdomen was seen in $10 \%$ of group A patients and $6.67 \%$ of group B patients.

There are studies for example by Akmal et al. showing better results with abdominal closure in continuous fashion. ${ }^{6}$ Other proponents mention interrupted closure technique to be better as far as wound dehiscence is considered. ${ }^{7}$ Similarly, Peponis et al. found out that wound dehiscence in interrupted suturing vs. continuous suturing was $2.7 \%$ vs. $2.4 \%$ respectively $(p=1.0) \cdot{ }^{14}$ As far as late wound complications are concerned, there is no uniform agreement as to which technique is better.

Hodgson et al. in their study concluded that abdominal fascial closure with a continuous non absorbable suture had a significantly lower rate of incisional hernia. ${ }^{12}$ While, Gupta et al. in their study, found out that the incisional hernias occur with the same frequency with both the interrupted technique of laparotomy wound closure and the continuous technique. ${ }^{16}$ 


\section{LIMITATIONS}

There are few limitations to this study. The sample size is small. Incidence of incisional hernia could not be studied properly in our study as the study of incidence of incisional hernia requires longer duration of follow-up, but the patients do not come for longer follow-up. The wound complications are higher in our study because only emergency cases were taken, hence this result cannot be considered for elective cases.

\section{CONCLUSION}

Continuous technique of midline laparotomy wound closure is better in terms of time required for closure and costing of suture material, while showing no difference in terms of wound infection, burst abdomen and late wound complications.

\section{REFERENCES}

1. Ellis $\mathrm{H}$. Midline abdominal incision. $\mathrm{Br} \mathrm{J}$ Obstet Gynecol. 1984;91(1):1-2.

2. Roses RE, Morris JB. Incisions, closures and management of abdominal wound. In: Zinner MJ, Ashley SW, editors. Maingot's abdominal operations. 12th ed. New York: The McGraw-Hill Companies; 2012:99-122.

3. Richards PC, Balch CM, Aldrete JS. Abdominal wound closure. A randomized prospective study of 571 patients comparing continuous vs. interrupted suture techniques. Ann Surg. 1983;197(2):238-43.

4. Karwasara RK, Dalal S, Bakshi V. Comparison of continuous versus interrupted abdominal fascia closure in patients of perforation peritonitis using polydioxanone (PDS) suture: a prospective study of 50 cases. IJARESM [Internet]. 2016 Feb [cited 2018 Mar 21];4(2):9-13. Available from:http://www.ijaresm.com/ uploaded_files/document_file/Dr_Vipul_BakshiXrID.pdf

5. Wadstrom J, Gerdin B. Closure of the abdominal wall; how and why? Clinical review. Acta Chir Scand. 1990;156(1):75-82.

6. Akmal $U$, Amini $A Q$, Afridi SP. Abdominal wound dehiscence in interrupted versus continuous closure of rectus sheath after midline emergency laparotomy incision. JSP. 2016;21(3):97-101.

7. Agrawal CS, Tiwari P, Mishra S, et al. Interrupted abdominal closure prevents burst: randomized controlled trial comparing interrupted-x and conventional continuous closures in surgical and gynecological patients. Indian J Surg. 2014;76(4):270-6.

8. Van 't Riet M, Steyerberg EW, Nellensteyn J, Bonjer HJ, Jeekel J. Metaanalysis of techniques for closure of midline abdominal incisions. Br J Surg. 2002;89(11):1350-6.

9. Fagniez P, Hay J, Lacaine F, Thomsen C. Abdominal midline incision closure: a multicentric randomized prospective trial of 3,135 patients, comparing continuous vs interrupted polyglycolic acid sutures. Arch Surg. 1985;120(12):1351-3.

10. Gislason H, Gronbech JE, Soreide O. Burst abdomen and incisional hernia after major gastrointestinal operations - comparison of three closure techniques. Eur J Surg. 1995;161(5):349-54.
11. Dhamnaskar SS, Sawarkar PC, Vijayakumaran P, Mandal P. Comparative study of efficacy of modified continuous smeadjones versus interrupted method of midline laparotomy fascial closure for contaminated cases. Int Surg J. 2016;3(4):1751-6.

12. Hodgson NC, Malthaner RA, Ostbye T. The search for an ideal method of abdominal fascial closure: a meta-analysis. Ann Surg. 2000;231(3):436-42.

13. Shashikala V, Abhilash SB, Abhishek G, Fernandes PS. A comparative study between continuous and $\mathrm{x}$-interrupted sutures in emergency midline laparotomies. Int Surg J. 2018;5(5):1753-57.

14. Peponis T, Bohnen JD, Muse S, et al. Interrupted versus continuous fascial closure in patients undergoing emergent laparotomy: a randomized controlled trial. J Trauma Acute Care Surg. 2018;85(3):459-65.

15. Ahi KS, Khandekar SM, Mittal SK, et al. Prevention of burst abdomen by interrupted closure: a comparative study of conventional continuous versus interrupted-X-type versus Hughes far-and-near interrupted abdominal fascial closure in surgical patients. IOSR JDMS. 2017;16(2):21-30.

16. Gupta H, Srivastava A, Menon GR, Agrawal CS, Chumber S, Kumar S. Comparison of interrupted versus continuous closure in abdominal wound repair: a meta-analysis of 23 trials. Asian J Surg. 2008;31(3):104-14. 